\title{
Asthma and allergic rhinitis co-morbidity: a cross-sectional questionnaire study on adolescents aged 13-14 years
}

\section{Cláudia Ribeiro de Andrade ${ }^{a}$ Cássio da Cunha Ibiapinab , Cristina Gonçalves Alvimb, Maria Jussara Fernandes Fontes ${ }^{b}$, Laura Maria de Lima Belizário Facury Lasmarb, *Paulo Augusto Moreira Camargos ${ }^{\mathrm{b}}$}

\author{
a José do Rosário Vellano University, Belo Horizonte, Brazil \\ ${ }^{\mathrm{b}}$ Department of Pediatrics, Pediatric Pulmonology Section, Federal University of Minas Gerais, Belo Horizonte, Brazil
}

Received 26th December 2007; revised 21st February 2008; accepted 23rd June 2008; online 13th August 2008

\begin{abstract}
Aims: There is scarce epidemiological population-based data on the prevalence of asthma and allergic rhinitis (AR) co-morbidity in adolescents. The aim was to verify asthma and AR prevalence rates in order to emphasise asthma/AR co-morbidity.

Methods: Cross-sectional study using the International Study of Asthma and Allergies in Childhood (ISAAC) questionnaire in adolescents aged 13-14 years, chosen randomly from public schools in Belo Horizonte, Brazil.

Results: A total of 3262 students were identified, 3083 (47.3\% males) of whom completed the questionnaire (response rate $94.7 \%$ ). The prevalence of symptoms related to asthma and AR co-morbidity was $8.4 \%$ (95\% Cl, 8.09-10.25). Among asthmatic adolescents, symptoms of AR were reported in $46.5 \%$ (95\% Cl, 42.60-52.08\%).

Conclusions: There is a high prevalence of adolescent asthma and AR co-morbidity in this area of Brazil. This co-morbidity is an important health issue that requires strategic application of primary health care facilities to achieve adequate control of both asthma and allergic rhinitis.

(C) 2008 General Practice Airways Group. All rights reserved.)

CR de Andrade et al. Prim Care Resp J 2008; 17(4): 222-225.

doi:10.3132/pcrj.2008.00056
\end{abstract}

Keywords allergic rhinitis, asthma, epidemiology, questionnaire, adolescents

\section{Introduction}

Asthma and allergic rhinitis (AR) co-morbidity refers to the association between asthma and AR. This is due to their physiopathological, epidemiological, and clinical similarities ${ }^{1-5}$ It is well known that patients with AR have changes in the bronchial mucosa despite the absence of asthma symptoms. Braunstahl et al. studied 16 patients with AR who had undergone bronchial biopsy; there was a reduction of lung and nasal function, as well as an increase in the number of eosinophils in nasal and bronchial mucosa, after bronchial provocation in non-asthmatic patients. ${ }^{6}$ Alternatively, patients with asthma have eosinophilic infiltrates in nasal mucosa despite the absence of AR symptoms. ${ }^{7.8}$
That asthma and AR are manifestations of the same inflammatory disease affecting the entire airway is further suggested by the clinical improvement of asthma when AR is treated. ${ }^{9}$ In a 3-year retrospective cohort study, Adams et al. identified 13,844 patients over five years old with asthma and verified that the number of emergency department visits was lower among patients having treatment for AR. ${ }^{9}$

Epidemiologically, there have been reports - mostly in ambulatory-based studies - showing high prevalence rates of $A R$ in asthmatic patients, with rates varying between 30$90 \% .^{10-13}$ However, population-based studies on the prevalence rates of asthma/AR co-morbidity are still scarce.

The present study aims to verify the prevalence of asthma

\footnotetext{
* Corresponding author: Professor Paulo Camargos, Departamento de Pediatria da Faculdade de Medicina da Universidade Federal de Minas Gerais, Avenida Professor Alfredo Balena, 190 / Sala 267, 30130-100 Belo Horizonte, Brazil.

Tel: +55 3134099772 Fax: +55 3134099664 E-mail: pcamargs@medicina.ufmg.br or pauloamcamargos@gmail.com
} 
and AR co-morbidity using the International Study of Asthma and Allergies in Childhood (ISAAC) Phase III survey in adolescents in Belo Horizonte, Brazil. It is expected that the results will contribute to recommendations for an integrated approach to treating asthma and $A R$ in public health programs in Brazil, especially in primary health care facilities.

\section{Methods}

The ISAAC protocol stated that the study population should consist of at least 3,000 students aged 13-14 years - in this case, enrolled in at least 10 randomly selected schools. ${ }^{14}$ The 13-14 year age group was chosen because it is the age most adolescents go to school regularly, making data collection easier.

Once requested by the research team, the municipal education authority provided a list of all 182 municipal schools and the number of students by school and grade. For operational reasons, schools with less than 200 eligible students were excluded. From the list of 43 remaining schools, 14 were selected from a random numeric list generated by software Epi Info 6.04 in order to reach the minimum of 3,000 students. The questionnaire was given to students aged 13-14 years in the seventh and eighth grades. Each school was visited at least twice to ensure a higher response rate and to minimise absenteeism.

The ISAAC questionnaire comprises eight questions about asthma-related symptoms, six about $A R$ and six rabout eczema. Translation of the questionnaire into Brazilian Portuguese, and validation, were properly carried out. ${ }^{15.6} \mathrm{An}$ affirmative and simultaneous answer, to both questions "Have you had wheezing or a whistling chest in the past 12 months?" and "In the past 12 months have you had problems with sneezing or a punny or blocked nose when you did not have flu?" was considered to confirm the prevalence asthma and AR symptoms, respectively. An affirmative answer to the two questions was considered to confirm the prevalence of asthma and AR co-morbidity. The prevalence of severe or moderate AR was confirmed by the answers, "a lot", or "a moderate amount", respectively, to the question, "In the last 12 months, how much did this nose problem interfere with your daily activities?" The prevalence of symptoms related to allergic rhinoconjunctivitis was confirmed by an affirmative answer to the AR question (above) and also to "In the past 12 months, has this nose problem been accompanied by itchy, watery eyes?" To estimate the prevalence rate of asthma and allergic rhinoconjunctivitis co-morbidity, an affirmative answer to both questions was required.

The questionnaire was completed by the adolescents in the classroom, under the supervision of at least one of the researchers, who were specially trained and briefed to avoid explanations that could interfere in the participants' answers.

As recommended by the WSAAC protocol, data entry and analysis were performeduising the software Epi Info 6.04. Frequency distribution of asthma, $A R$, allergic rhinoconjunctivitis, and the co-morbidities of asthma/AR and asthma/allergic rhinoconjunctivitis were calculated with 95\% confidence intervals (Cl). To assess any association between allergic rhinitis/asthma symptom prevalence and sex we used Yates' chi-square and odds ratios (OR).

The study protocol and informed consent were approved Oby the Ethical Research Committee of the Federal University of Minas Gerais, Brazil.

\section{Results}

Initially, 3,262 students aged 13-14 were identified and given a single questionnaire; 3,083 completed it, giving a response rate of $94.7 \%-47.3 \%$ males and $45.8 \%$ aged 13 years. The demographic characteristics and the prevalence of symptoms related to $A R$, allergic rhinoconjunctivitis, asthma, and

Table 1. Demographic characteristics and prevalence rate of asthma, asthma/allergic rhinitis and asthma/allergic rhinoconjunctivitis co-morbidities.

\begin{tabular}{|c|c|c|c|c|}
\hline Characteristics & & $\mathrm{n}$ & $\%$ & $95 \% \mathrm{Cl}$ \\
\hline \multirow[t]{2}{*}{ Sex } & Male & 1,458 & 47.3 & $45.5-49.1$ \\
\hline & Female & 1,625 & 52.7 & $50.9-54.4$ \\
\hline \multirow[t]{2}{*}{ Age (years) } & 13 & 1,413 & 45.8 & $44.1-47.6$ \\
\hline & 14 & 1,670 & 54.2 & $52.4-55.9$ \\
\hline \multirow[t]{4}{*}{ Prevalence symptoms related to } & Asthma and allergic rhinitis & 255 & 8.4 & $8.1-10.3$ \\
\hline & co-morbidity & & & \\
\hline & Asthma and allergic rhinoconjunctivitis & 164 & 5.3 & $4.6-6.2$ \\
\hline & co-morbidity & & & \\
\hline
\end{tabular}


asthma/AR and asthma/allergic rhinoconjunctivitis comorbidity, are presented in Table 1.

Among adolescents with asthma, the prevalence of AR was $46.8 \%(95 \% \mathrm{Cl}$, range $42.6-52.0)$; i.e. $8.4 \%$ of the total participants $(95 \% \mathrm{Cl}, 8.0-10.2)$ presented symptoms related to asthma and AR co-morbidity. Prevalence of severe AR among asthmatics was $21.6 \%(95 \% \mathrm{Cl}, 16.8-27.1)$, corresponding to $3.8 \%$ of participants. Furthermore, prevalence of asthma and allergic rhinoconjunctivitis co-morbidity was $5.3 \%$ of the total sample $(95 \% \mathrm{Cl}, 4.6-6.2)$, corresponding to $29.9 \%$ of the patients with asthma. Male sex was a protective factor (OR 0.72 , $95 \% \mathrm{Cl}, 0.55-0.94, \mathrm{p}=0.01$ ) for asthma and AR co-morbidity.

\section{Disaussion}

In ambulatory-based studies, the prevalence rates of asthma and AR co-morbidity range from 30 to $90 \% \cdot{ }^{10-13}$ In a study from Turkey, $68.8 \%$ of 369 children and adolescents aged from 3 to 16 years with asthma also had AR. ${ }^{11}$ Similar findings were described by Sichletidis et al. from Greece, in a crosssectional study in which $69 \%$ of children with asthma also presented symptoms of $A R .^{13}$ Since these studies were performed in ambulatory patients, extrapolation of the results to the general population is limited, stressing the need for population-based studies.

Prevalence of asthma and AR co-morbidity using the ISAAC methodology has been reported previously, even though this was not a primary aim of the study. ${ }^{17}$ Sole et al verified that in the city of São Paulo, Brazil, among adolescents aged 13-14 years reporting asthma symptoms, $42 \%$ reported symptoms compatible with $A R$, a very similar rate to the present study. The criteria for defining asthma and AR were the same used in the present study, but the authors did not assess the association between asthma and allergic rhinoconjunctivitis.

Most studies referring to the ISAAC results present isolated prevalences of symptoms of asthma, eczema, and allergic rhinoconjunctivitis, but not AR. Among them, some report prevalence rates of asthma and allergic rhinoconjunctivitis co-morbidity ranging from 3.4 to $5.3 \%,{ }^{14,18-21}$ similar to the present study.

Worldwide data from ISAAC phase I shows that the proportion of adolescents with symptoms compatible with asthma and allergic rhinoconjunctivitis co-morbidity was $3.3 \%$, corresponding to $50 \%$ of patients reporting asthma symptoms ${ }^{14}$ whereas in phase III, the proportion was $3.5 \% .{ }^{18}$ The results of this study show that $10 \%$ of the study population had symptoms compatible with asthma and $A R$ co-morbidity. This stresses the importance of this co-morbidity as a health concern.

A limitation of our study is that the results are only generalisable in the age group that we evaluated. There are approximately 82,000 adolescents between the age of 13-14 in Belo Horizonte; ${ }^{22}$ extrapolation of these results would suggest that 6,900 of them have asthma/AR co-morbidity. One can therefore assume that a significant amount of them would benefit from combined treatment with intranasal and inhaled steroids. On a national level, the situation is likely to be the same, since the prevalence rates of asthma and AR are similar to those found in Belo Horizonte. ${ }^{23}$ Further studies are required to estimate the prevalence of asthma and allergic rhinitis co-morbidity in other countries.

The recognition and treatment of asthma and AR comorbidity in clinical practice and by public health authorities is crucial. Several studies suggest that improvement in asthma and AR control leads to a reduction in healthcare resource use; it has been demonstrated that untreated AR hinders asthma control, ${ }^{24,25}$ and can lead to an increase in exacerbations and medication use. .6,27 $^{2}$

Sazonov Kocevar et al. followed 2,961 children with a history of hospitalisations for asthma and found that the risk of readmission among asthmatics with AR was 1.72 times higher than in asthmatics without AR. Moreover, AR was predictive of $\mathrm{a}$ higher number of days of hospitalisation/year among asthmatics patients. ${ }^{27}$ In addition, treatment of AR leads to improvements in asthma - as reported in studies observing a decrease in hospitalisation rates or emergency departments visits in patients with asthma and AR receiving Ointranasal corticosteroids. ${ }^{28,29}$

The Global Initiative for Asthma (GINA) ${ }^{30}$ recognises that $A R$ is frequently associated with asthma and that AR needs to be treated in order to achieve good asthma control - in accordance with Allergic Rhinits and its Impact on Asthma recommendations. ${ }^{1}$ Patients with both conditions can be treated with nasal and inhaled glucocorticosteroids, with or without a leukotriene modifier, depending on the severity of the condition, their level of control, and local resources. Dosages of inhaled and nasal glucocorticosteroids must be titrated and possibly reduced if used concomitantly.

The present study shows the relevance of this health problem, and corroborates the recommendations of the World Health Organization (WHO) regarding an integrated diagnostic, therapeutic, and prophylactic approach to AR and asthma. 'Recently the WHO Global Alliance against Chronic Respiratory Diseases (GARD) also proposed suitable management of chronic respiratory diseases, including asthma and AR, according to local needs. ${ }^{31}$

Therefore, public health authorities must be aware of the importance of respiratory diseases, and must recognise that primary care programs must not involve asthma alone. As we have seen in the ProAR Program in Bahia, Brazil, treating patients with both asthma and AR appropriately is important; this led to a $90 \%$ decrease in the number of hospitalisations 
and an $85 \%$ reduction in emergency department visits. ${ }^{32}$

In conclusion, the results obtained in the present study stress the need for asthma programs to consider patients with asthma and AR co-morbidity. This should lead to better symptom control and reduce the use of healthcare resources. Primary care physicians should examine all asthmatic patients for allergic rhinitis/allergic rhinoconjunctivitis, and vice-versa, and should prescribe suitable treatment when indicated.

\section{Conflicts of interest}

There are no competing interests for any of the authors.

\section{References}

1. ARIA Workshop Report Allergic rhinitis and its impact on asthma. J Allergy Clin Immunol 2001;108(suppl 5):147-334.

2. Kapsali $T$, Horowitz E, Miemer F, Togias A. Rhinitis is ubiquitous in allergic asthmatics. J Allergy Clin Immunol 1997;99:S138.

3. Nayak AS. The asthma and allergic rhinitis link. Allergy Asthma Proc 2003;24:395-402.

4. Passalacqua G, Ciprandi G, Canonica WC. The nose-lung interation in allergic rhinitis and asthma: united airways disease. Curr Opin Allergy Clin Immunol 2001;1:7-13.

5. Cruz AA. The "united airways" require a holistic approach to management. Allergy 2005; 60:871-4.

6. Braunstahl GJ, Kleinjan A, Overbeek SE, Prins JB, Hoogsteden HC, Fokkens WJ. Segmental bronquial provocation induces nasal inflammation in allergic rhinitis patients. Am J Respir Crit Care Med 2000;161:2051-7.

7. Gaga M, Lambrou P, Papageorgiou N, et al. Eosinophils are a feature of upper and lower airway pathology in non-atopic asthma, irrespective of the presence of rhinits. Clin Exp Allergy 2000;20:663-9.

8. Magalhães Simões S, Santos MA, Oliveira MS, Fontes ES, Fernezlan S, Garippo L. Inflamatory cell mapping of the respiratory tract in fataDasthma. Elin Exp Allergy 2005;35:602-11.

9. Adams R, Fuhlbrigge A, Finkelstein JA, Weiss, S Intranasal stergids and the risk of emergency departament visits for asththa. I Aleprgy Clin Immunol 2002; 109:57-62.

10. Leynaert B, Neukirch F, Demoly (P) Bousquet J. Epidemiologic evidence for asthma and rhinitis comorbidity. J Allergy Clin Immunol 2000;106(5 Suppl): S201-5.

11. Kocabas CN, Civelek E, Sackesen C et al. Burden of rhinitis in children with asthma. Pediatr Pulmonol 2005;40:235-40.

12. Gurkan F, Davutoglu M, Bilici M, Dagli A, Haspolat K. Asthmatic children and risk factors at a province in the southeast of Turkey. Allergol Immunopathol (Madr) 2002;30:25-9.

13. Sichletidis $L$, Chloros $D$, Tsiotsios I et al. The prevalence of allergic asthma and rhinitis in children of Polichni, Thessaloniki. Allergol Immunupathol (Madr) 2004;32:59-63.

14. Worldwide variation in prevalence of symptoms of asthma, allergic rhinoconjunctivitis, and atopic eczema: ISAAC. International Study of Asthma and Allergies in Childhood (ISAAC) Steering Committee. Lancet 1998;351:1225-32.

15. Solé D, Vanna AT, Yamada E, Rizzo MC, Naspitz CK. International Study of Asthma and Allergies in Childhood (ISAAC) written questionnaire: validation of the asthma component among brazilian children. I Invest Allergol Clin
Immunol 1998;8:376-82.

16. Vanna AT, Yamada E, Arruda LK, Naspitz CK, Solé D. International Study of Asthma and Allergies in Childhood: validation of the rhinitis symptom questionnaire and prevalence of rhinitis in São Paulo, Brazil. Pediatr Allergy Immunol 2001;12:95-101.

17. Solé D, Camelo-Nunes IC, Wandalsen GF, Melo KC, Naspitz CK. Is rhinitis alone or associated with atopic eczema a risk factor for severe asthma in children? Pediatr Allergy Immunol 2005;16:121-5.

18. Ascher $\mathrm{M}$, Montefort $\mathrm{S}$, Bjorstén $\mathrm{B}$, et al. Worldwide time trends in the prevalence of symptoms of asthma, allergic rhinoconjunctivitis, and eczema in childhood: ISAAC Phases One and Three repeat multicountry cross-sectional rates. Lancet 2006;368:733-43.

19. Ait- Khaled N, Odhiambo J, Pearce N, et al. Prevalence of symptoms of asthma, rhinitis and eczema in 13-to 14- year-old children in Africa: The International Study of Asthma and Allergies in Childhood Phase III. Allergy 2007;62:24758.

20. Foliaki S, Annesi-Maesano I, Daniel R, et al. Prevalence of symptoms of childhood asthma, allergic rhinoconjunctivitis and eczema in the Pacific. The International Study of Asthma and Allergies in Childhood (ISAAC). Allergy 2007;62:259-64.

21. Mavale-Manuel $S$, Joaquim $O$, Macome $C$, et al. Asthma and allergies in schoolchildren of Maputo. Allergy 2007;62:265-71.

22. Ministério da Saúde, do Brasil. [Internet site]. Avaiable from http://tabnet.datasus.gov.br/cgi/deftohtm.exe?ibge/cnv/popmg.def. Acessed 1 July 2007.

23. Solé $D_{r}$, Wandalsen G, Camelo-Nunes I, Naspitz CK; ISAAC Grupo Brasileiro. Prevalence of symptoms of asthma, rhinitis and atopic eczema among Brazilian children and adolescents identified by the International Study of Asthma and Allergies in childhood (ISAAC)-Phase 3. J Pediatr (Rio J) 2006;82:341-6.

24. Leynaert B, Bousquet J, Nekirch, Liard R, Neukirch F. Perennial rhinitis: an independent risk factor for asthma in nonatopic subjects. I Allergy Clin Immunol 1999; 104:301-04.

25. Corren J. The rhinitis-asthma link revisited. Ann Allergy Asthma Immunol 2005; $94: 311-12$.

26. Lozano P, Fischman P, Vonkorff M, Hecht J. Health care utilization and cost among children with asthma who were enrolled in health maintenance organization. Pediatrics 1997;99:757-64.

27. Sazonov Kocevar $V$, Thomas III J, Jonsson $L$ et al. Association between allergic rhinitis and hospital resource use among asthmatic children in Norway. Allergy 2005:60:338-42.

28. Crystal-Peters J, Neslusan C, Crown WH, Torres A. Treating allergic rhinitis in patients with comorbid asthma: The risk of asthma-related hospitalizations and emergency department visitis. J Allergy Clin Immunol 2002;109:57-62.

29. Corren J, Manning BE, Thompson SF et al. Rhinitis therapy and the prevention of hospital care for asthma: a case-control study. I Allergy Clin Immunol 2004;113:415-19

30. National Institutes of Health. National Heart, Lung and Blood Institute. Global Initiative for Asthma. Global strategy for asthma management and prevention. Bethesda: NIH 2006.

31. Bousquet J, Dahl R, Khaltaev N. Global Alliance against Chronic Respiratory Diseases. Eur Respir J 2007;29:233-9.

32. Ponte E, Franco RA, Souza-Machado A, Cruz AA. Impacto de um programa para controle da asma grave na utilização de serviços do Sistema Único de Saúde. J Bras Pneumol 2007;33:15-19.

\section{Available online at http://www.thepcrj.org}

